\title{
High-Throughput Analysis of Lignin by Agarose Gel Electrophoresis
}

\author{
Christopher A. Holt, Betty Cottyn, Stephanie Baumberger, Krisztina Kovacs-Schreiner, \\ and A. John Blacker*
}

Cite This: J. Agric. Food Chem. 2020, 68, 14297-14306

Read Online

\section{ACCESS | Lلll Metrics \& More | 国 Article Recommendations | Sl Supporting Information}

ABSTRACT: A high-throughput agarose gel electrophoresis (AGE) analytical method has been developed to separate lignin fractions according to their molecular weight $\left(M_{\mathrm{w}}\right)$, charge, and shape. Operating conditions to effect separation of species have been evaluated along with imaging parameters. Kraft, soda (Protobind), and Organosolv lignins showed distinct differences in migration. Bands were cut, extracted, and cross-analyzed by gel permeation chromatography (GPC), ${ }^{1} \mathrm{H}$ NMR, and pyrolysis GC/MS to confirm their identity as lignin. The band intensity was correlated with lignin concentration by running serially diluted samples and imaging each lane to produce a precise calibration curve. The AGE technique was used to monitor and compare enzymatic, bacterial, chemical, and hydrothermal lignin digestions. Each method showed changes in lignin migration and band intensities over time. Low $M_{\mathrm{w}}$ species were seen in samples collected from the anode buffer tank. Though requiring further development, the AGE method can provide structural information about the lignin and is accessible to biological and chemistry laboratories.

KEYWORDS: lignin, agarose gel electrophoresis, depolymerization, electrophoretic migration, high-throughput analysis

\section{INTRODUCTION}

Lignin is the second most abundant organic biopolymer on Earth and is highly variable across different plant species. ${ }^{1}$ It is of intense current interest as a renewable source of aromatic compounds with the idea that it might provide the chemical industry with at least a partial replacement for related oilderived products. $^{2-5}$ Methods for its deconstruction are varied and include thermal (pyrolysis), thermochemical (alkaline, acidic, oxidative, or reductive), hydrothermal (autocatalytic acid hydrolysis), and biological (insecticidal, microbial, or enzymatic) methods. ${ }^{6,7}$ Because of its complex heterogeneous structure, developing analytical methods to compare the depolymerization performance of these methods is a challenge. To date, this has relied on discrete analytical techniques that are poorly suited to large numbers of samples that arise in studies relative to lignin depolymerization. ${ }^{8,9}$ A widely used method to determine the lignin content is the gravimetric Klason procedure, which requires several hundred milligrams of sample. ${ }^{10}$ Derivatization with acetyl bromide allows much smaller quantities of lignin to be used but is unreliable without a standard and suffers contaminant species also absorbing at $280 \mathrm{~nm} .{ }^{11}$ On the other hand, colorimetric determination methods like the Folin-Ciocalteu, ABTS, and DPPH techniques measure indirectly the total phenolic content of lignin samples but are prone to overestimation when reducing sugars are present, e.g., from (hemi)cellulose, and provide little structural information. ${ }^{12-14}$ Assessment of the lignin molecular weight distribution is commonly performed through GPC, which provides the apparent average molecular weight in weight $\left(M_{\mathrm{w}}\right)$ and in number $\left(M_{\mathrm{n}}\right) .^{15-17}$ However, this technique generally requires extraction of the phenolic compounds from an aqueous reaction medium by organic solvent, evaporation, derivatization, dissolution in the final solvent (usually THF), and filtration before injection, which requires no less than $48 \mathrm{~h}$ and can lead to artifacts due to only partial solubility. A further problem is that derivatization results in charge neutralization, and this can alter lignin's tertiary structure and the apparent $M_{\mathrm{w}}$ and $M_{\mathrm{n}}{ }^{18}$ Moreover, the GPC column is calibrated using polystyrene standards which are considerably different from lignin and provide relative rather than absolute information. Nevertheless, this method remains useful for lignin classification and detection of overall structural modifications. Direct analysis is possible by aqueous and polar solvent-based GPC but only for soluble lignins. ${ }^{19,20}$ Detection modes combined with GPC are UV, refractive index, or light-scattering detection. ${ }^{21,22}$ The $M_{\mathrm{w}}$ of lignins varies between species and with the method of isolation and measurement. Reported ranges are from 4500 (pine/ spruce lignoboost lignins) to $78400 \mathrm{~g} / \mathrm{mol}$ (Norwegian spruce lignosulfonates) with dispersities $\left(M_{\mathrm{w}} / M_{\mathrm{n}}\right)$ around $4 .^{23,24}$ Besides information on the $M_{\mathrm{w}}$ distribution, some structural characteristics of lignin are useful to assess depolymerization, such as interunit bonds and functional groups. A variety of multidimensional ${ }^{1} \mathrm{H}$ and ${ }^{13} \mathrm{C}$ NMR techniques can be used for this purpose. $^{25-27}$ Once again, these techniques are time consuming, require expertise to generate and interpret data, and are not suited to high-throughput screening of depolymerization conditions.

Since agarose gel electrophoresis (AGE) was first described, ${ }^{28}$ it has been used commonly for characterization

Received: October 1, 2020

Revised: October 28, 2020

Accepted: November 4, 2020

Published: November 17, 2020

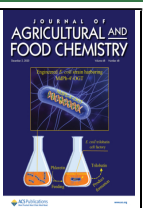


of polynucleic acid anions and proteins and even carbon nanotubes. ${ }^{29-31}$ Lignin electrophoresis has been mentioned in only three reports, ${ }^{32,33}$ with neither exploring its potential for separation nor characterization of lignin samples. There is a report of isoelectric focusing of $\operatorname{lignin}^{34}$ and one describing capillary zone electrophoresis (CZE) for determination of the lignin content in black liquor. ${ }^{35}$ Agarose gel electrophoresis (AGE) involves applying an electric field across a cast gel immersed in a conducting electrolytic buffer, Figure 1.

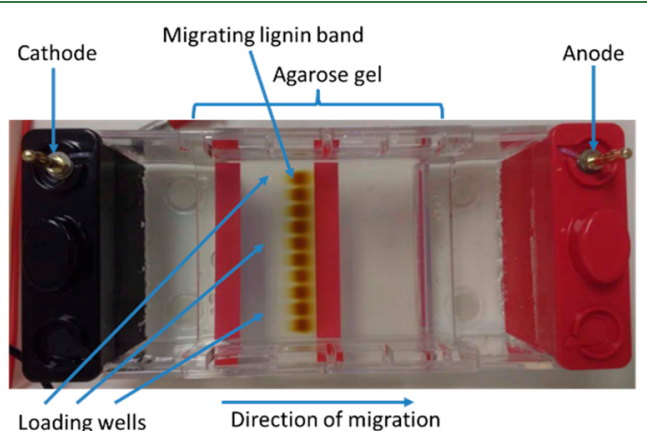

Figure 1. Agarose minigel electrophoresis tank with brown migrating lignin bands.

While CZE is rapid and requires only tiny sample sizes, AGE has several advantages that include the ability to simultaneously separate large numbers of samples in a short time, making it a high-throughput method, direct comparison of migrating bands, the ability to cope with particulates and detect compounds that do not migrate, and extraction of separated samples and preparative methods.

At higher $\mathrm{pH}$ 's, lignin becomes a polyanion as free phenolic groups ionize around $\mathrm{pH} 9-10$ and like nucleic acids should migrate toward the anode. Agarose gels consist of pores which retard the movement of larger molecules with respect to smaller ones. ${ }^{36}$ Gels are typically produced by dissolving purified agarose in a hot buffer and casting the solution in a rectangular tray that solidifies upon cooling. A comb placed in the liquid gel creates individual wells in which the analyte solutions can be placed. As a result, compounds can be separated based on $M_{w}$, charge, and shape, for example, linear, circular, and supercoiled DNA which has been used to test cleavage reagents. ${ }^{37,38}$ This paper assesses the possibility to transfer the AGE technique to the investigation of various lignin depolymerization processes and to elucidate the lignin structural parameters governing their migration. With their low environmental impact, enzymatic and microbial lignin depolymerizations are being widely researched to access aromatic monomers, while hydrothermal treatments are being evaluated for energy and material applications. Chemical treatments are used widely in paper and pulping operations. We report herein the use of electrophoresis in separating lignin and its use in monitoring deconstruction processes.

\section{MATERIALS AND METHODS}

General. Chemicals were purchased from Sigma-Aldrich, except agarose and boric acid which were from Thermo Fisher Scientific. Kraft lignin samples KL2 and KL1, produced using high and low $M_{\mathrm{w}}$ cutoff membranes, were purchased from 8317267 Canada Inc. Protobind lignins PB1, PB2, and PB3 were purchased from GreenValue Ltd. Organosolv lignins OS1, OS2, and OS3 were provided by the Energy Research Centre of The Netherlands (ECN). They corresponded to three distinct pulping conditions, as described by Aguié-Béghin et al. ${ }^{39}$ Alkali lignin low sulfonate content was purchased from Sigma-Aldrich. EasiCal polystyrene standards used for GPC molecular weight calibration were purchased from Agilent Technologies. Rhodococcus jostii pTipQ2-ligAB was kindly provided by Prof. Tim Bugg (Warwick University). Pseudomonas putida KT2440 strain (DSM number 6125) was purchased from the DSMZ. The laccase enzymes used in this work were purchased from MetGen. ${ }^{38}$ Sodium borate (SB) buffer was made of $36 \mathrm{mM}$ boric acid and $10 \mathrm{mM}$ sodium hydroxide. TAE buffer was made of 40 $\mathrm{mM}$ Tris base, $20 \mathrm{mM}$ acetic acid, and $1 \mathrm{mM}$ EDTA.

For gel imaging, it is better to have low-intensity light produced on a completely dark background than high emission on a light-emitting background. Imaging was carried out with a ChemiDocTM MP Imaging System by exposing to light from 650 to $675 \mathrm{~nm}$ and measuring emission at $700-730 \mathrm{~nm}$ unless otherwise stated. Gel analysis was carried out using ImageJ (a program developed by the National Institutes of Health and accessible online, https://imagej. nih.gov/ij/). Using the software, gel bands were selected (with fixed selection dimensions and fixed vertical alignment) and processed using the in-built gel functions (ESI 2).

Preparation of Lignin Samples for Electrophoresis. Samples of Kraft lignin $\mathrm{KL} 1$ were diluted in water to $5 \mathrm{~g} / \mathrm{L}$ unless otherwise stated. Samples of Kraft lignin KL2 were dissolved in water by dropwise addition of $5 \mathrm{M} \mathrm{NaOH}$ before readjusting to $\mathrm{pH} 7$ with $\mathrm{HCl}$. Samples of Protobind were made by adding $2 \mathrm{~mL}$ of SB buffer to $10 \mathrm{mg}$ of lignin. Samples of Organosolv were made by adding $0.5 \mathrm{~mL}$ of SB buffer to $30 \mathrm{mg}$ of lignin. The lignin mixtures were sonicated for $10 \mathrm{~min}$ and then centrifuged at $2880 \mathrm{~g}$ for $15 \mathrm{~min}$ to separate the soluble from the insoluble fraction of the lignin. The soluble fraction was then used for electrophoresis.

Standard Conditions for Mini- and Maxiagarose Gels. A Clarit-E Mini gel tank was used with a $10 \times 2 \mathrm{~mm}$ comb for thick wells to enable high sample loading. A Clarit-E Maxi gel tank had 40 $\times 1 \mathrm{~mm}$ comb for narrow wells. The agarose gels were made using $1 \%$ $(\mathrm{w} / \mathrm{v})$ agarose in SB buffer, heating the slurry to $\sim 100{ }^{\circ} \mathrm{C}$ until the solution became clear, and allowing it to cool to $60^{\circ} \mathrm{C}$ before pouring into a gel mold using a comb to define the loading wells. When using the Clarit-E Maxi gel tank, the gels were poured on a leveled Flexicaster to ensure a uniform gel thickness, which was found to markedly affect the fluorescence consistency (ESI S1.7). The gel was formed after around $30 \mathrm{~min}$, and SB buffer was poured into the tank to submerge the gel. Dust causes problems with the gel and image analysis and was minimized by ensuring all equipment and solutions were clean using lens cleaning tissues to remove any residual dust. Lignin samples were prepared in Eppendorf tubes by mixing $40 \mu \mathrm{L}$ of $50 \%(\mathrm{w} / \mathrm{v}$ ) glycerol, $40 \mu \mathrm{L}$ of $0.375 \mathrm{M} \mathrm{NaOH}$ (ESI S1.5), and $100 \mu \mathrm{L}$ of a $5 \mathrm{~g} / \mathrm{L}$ lignin sample before mixing using a vortex mixer. The minigel was charged with $20 \mu \mathrm{L}$ of sample/lane using a Gilson pipet. The maxigel was charged using a multichannel pipet. The multichannel pipet channels do not directly line up with every gel well due to the tight spacing of the wells, so every other lane was loaded at a time, as shown in ESI S1.1. After loading, samples were equilibrated with buffer in the pocket for at least $30 \mathrm{~min}$ to give more consistent band migration (ESI S1.2 and S1.3). Power was supplied from a BioRad PowerPac 300 to apply a fixed voltage across the gel. Electrophoresis was typically carried out at a fixed voltage of $50 \mathrm{~V}$ for $60 \mathrm{~min}$.

Preparative Methods and Extraction of Lignin from the Agarose. Electrophoresis was carried out at $50 \mathrm{~V}$ for $40 \mathrm{~min}$ in a minigel tank with SB buffer and a $0.75 \%$ agarose gel using a $2 \mathrm{~mm}$ comb to load more lignin onto the gel. Alkali lignin was dissolved in water $(300 \mathrm{~g} / \mathrm{L})$ and $\mathrm{Kraft} \mathrm{KL} 1(200 \mathrm{~g} / \mathrm{L})$. A $25 \mu \mathrm{L}$ amount of the lignin sample was then mixed with $10 \mu \mathrm{L}$ of $50 \%$ glycerol before loading onto the gel. Once complete, the main band, or fractions of it, was cut across the 8 lanes using a scalpel (ESI S1.10 and S3.3). The excised gel was then freeze dried and ground into a fine powder using a pestle and mortar. The powder was then added to a flask with 100 $\mathrm{mL}$ of distilled water, stirred overnight, and filtered through a glass filter tube. Concentrated $\mathrm{HCl}$ was then added to precipitate the lignin, and the mixture was kept at $4{ }^{\circ} \mathrm{C}$ overnight. The solution was then 
Table 1. Variables Tested in Defining Conditions for Electrophoresis of Kraft Lignin KL1

\begin{tabular}{|c|c|c|c|}
\hline entry & variable & range tested & selected condition \\
\hline 1 & sample & $0.63-214 \mathrm{~g} \cdot \mathrm{L}^{-1}$ lignin & $\begin{array}{l}10 \mu \mathrm{L} \text { from a mixed Eppendorf containing } 20 \mu \mathrm{L} \text { of } 50 \% \text { glycerol }+20 \mu \mathrm{L} \text { of } 375 \mathrm{mM} \mathrm{NaOH} \\
+50 \mu \mathrm{L} \text { of } 5 \mathrm{~g} \cdot \mathrm{L}^{-1} \text { lignin }\end{array}$ \\
\hline 2 & buffer & $\begin{array}{l}\text { tris-acetate-EDTA (TAE) pH } 7.75 \text {, } \\
\quad 8.32,8.75 \\
\text { sodium borate }(\mathrm{SB}) \mathrm{pH} 7.75,8.32 \text {, } \\
8.75\end{array}$ & sodium borate $36 \mathrm{mM}, \mathrm{pH} 8.75$ \\
\hline 3 & agarose strength & $0.5-2 \%(\mathrm{w} / \mathrm{v})$ & $1 \%(\mathrm{w} / \mathrm{v})$ \\
\hline 4 & voltage/current & $50-120 \mathrm{~V} / \sim 1000-420 \mathrm{~mA}$ & $50 \mathrm{~V} / \sim 1000 \mathrm{~mA}$ \\
\hline 5 & $\begin{array}{l}\text { time and retention } \\
\text { factor }\left(R_{f}\right)\end{array}$ & $\begin{array}{l}20-240 \mathrm{~min} \\
0.125-0.9 R_{f}\end{array}$ & $60 \mathrm{~min} ; R_{f} \approx 0.45$ \\
\hline 6 & visualization & $400-800 \mathrm{~nm}$ irradiation/emission & irradiation $650-675 \mathrm{~nm}$; emission $700-730 \mathrm{~nm}$ \\
\hline 7 & $\begin{array}{l}\text { gel and image } \\
\text { analysis }\end{array}$ & ethidium bromide; $\mathrm{SyBr}$ safe; no dye & no dye; ImageJ and ChemiDocMP \\
\hline
\end{tabular}

centrifuged at $4500 \mathrm{rpm}$ for $15 \mathrm{~min}$, the supernatant discarded, and the pellet freeze dried ready for further analysis. The recovered yield of KL1 lignin was $\sim 83 \%$ based on the mass.

Evidence That the Migrating Bands Are Lignin. Preparation of samples for GPC was carried out by precipitating the soluble lignin from water by adding $1 \mathrm{~mL}$ of $6 \mathrm{~N} \mathrm{HCl}$. After $24 \mathrm{~h}$ the Organosolv, Protobind, and Kraft lignin solutions were centrifuged at $2880 \mathrm{~g}$ for 15 $\min$ at $4{ }^{\circ} \mathrm{C}$, the supernatant was discarded, and the pellet was freeze dried. Acetylation was carried out on $10 \mathrm{mg}$ of each lignin mixed with $0.6 \mathrm{~mL}$ of a $2: 1$ solution of acetic anhydride and pyridine left at room temperature for $24 \mathrm{~h}$. A $0.2 \mathrm{~mL}$ amount of ice cold methanol was added to quench the reaction, the solvent evaporated under vacuum, then $0.2 \mathrm{~mL}$ of toluene added, mixed, and evaporated. The solvent washing procedure was repeated twice more. The remaining acetylated lignin sample was then freeze dried. A $1 \mathrm{~mL}$ amount of of THF was added to dissolve the sample which was then filtered using a $0.45 \mu \mathrm{m}$ PTFE filter. The sample was then ready for GPC. GPC was carried out with THF as eluent at $1 \mathrm{~mL} / \mathrm{min}$ using an Agilent PLgel MIXED-C column using an UltiMate 3000 Autosampler Column Compartment for sample handling and an UltiMate 3000 Photodiode Array Detector. Chromeleon software was used for sample analysis. GPC plots were normalized by expressing the arbitrary units (mAU) values as a percentage of the highest mAU value for each respective sample.

Enzymatic Digestion of Lignin. Enzyme treatment was carried out in a $250 \mathrm{~mL}$ conical flask with a total reaction volume of $50 \mathrm{~mL}$ containing $5 \mathrm{~g} / \mathrm{L} \mathrm{KL} 1 \mathrm{Kraft}$ lignin, $70 \mathrm{mM} \mathrm{pH} 7$ potassium phosphate buffer, 11.8 units of the MetZyme LIGNO laccase enzyme mixture, and $0.55 \mathrm{mM}$ syringaldehyde $(100 \mu \mathrm{L}$ of a $275 \mathrm{mM}$ stock solution dissolved in methanol) used as laccase redox mediator. ${ }^{40}$ The control sample was identical in composition and volume except for the presence of enzyme. A $1 \mathrm{~mL}$ amount of sample was taken preincubation and at the respective time points and centrifuged for $15 \mathrm{~min}$ at $4500 \mathrm{rpm}$; the supernatant was then used for electrophoresis. Enzymatic digestion was carried out on a shaker incubator at $180 \mathrm{rpm}$ set at $37^{\circ} \mathrm{C}$.

Bacterial Digestion of Lignin. All bacterial growth was carried out with a working volume of $50 \mathrm{~mL}$ in $250 \mathrm{~mL}$ conical flasks in a shaking incubator at $30{ }^{\circ} \mathrm{C}$ and $180 \mathrm{rpm}$. Degradation conditions were $\mathrm{pH} 7$ sterilized $\mathrm{M} 9$ media containing $6.78 \mathrm{~g} / \mathrm{L} \mathrm{Na}_{2} \mathrm{HPO}_{4}, 3 \mathrm{~g} / \mathrm{L}$ $\mathrm{KH}_{2} \mathrm{PO}_{4}, 1 \mathrm{~g} / \mathrm{L} \mathrm{NH} \mathrm{N}_{4} \mathrm{Cl}, 0.5 \mathrm{~g} / \mathrm{L} \mathrm{NaCl}$, and $1.5 \mathrm{~g} / \mathrm{L} \mathrm{KL} 1 \mathrm{Kraft}$ lignin. ${ }^{41}$ The following elements were added after sterilization with a syringe filter with a $0.2 \mu \mathrm{m}$ pore size: $2 \mathrm{mM} \mathrm{MgSO}_{4}, 100 \mu \mathrm{M} \mathrm{CaCl}_{2}$, $100 \mu \mathrm{M} \mathrm{CuSO}_{4}, 100 \mu \mathrm{M} \mathrm{MnSO}_{4}, 100 \mu \mathrm{M} \mathrm{FeSO}_{4}, 100 \mu \mathrm{M} \mathrm{ZnSO}_{4}$, and $0.1 \mathrm{~g} / \mathrm{L}$ vanillic acid to supplement growth for $R h$. jostii and $10 \mathrm{~g} /$ $\mathrm{L}$ glucose for Ps. putida. For the Rh. jostii experiments, $50 \mu \mathrm{g} / \mathrm{mL}$ chloramphenicol dissolved in ethanol was added (without thiostreptone inducer). Prior to inoculation into the media, Rh. jostii and Ps. putida were grown in LB medium for $24 \mathrm{~h}$ and used to inoculate the above media to a starting OD600 of 0.1. No bacteria were added to the control sample. A $1 \mathrm{~mL}$ amount of sample was taken at specific time points and centrifuged for $15 \mathrm{~min}$ at $4500 \mathrm{rpm}$ to pellet the bacteria; the supernatant was then used for electrophoresis.

To test removal of adsorbed proteins, $40 \mu \mathrm{L}$ of $10 \mathrm{mg} / \mathrm{mL}$ proteinase $\mathrm{K}$ solution was added to $1 \mathrm{~mL}$ of $1.5 \mathrm{~g} / \mathrm{L}$ Ps. putida-treated KL1 lignin solution. The mixture was then incubated overnight in a shaking incubator at $200 \mathrm{rpm}$ set at $37{ }^{\circ} \mathrm{C}$. The sample was then centrifuged at $4500 \mathrm{rpm}$ for $15 \mathrm{~min}$, and the supernatant was used for electrophoresis. For the heat treatment test, $1 \mathrm{~mL}$ of the Ps. putida sample was heated to $95^{\circ} \mathrm{C}$ for 5 min using a heat block. The sample was then centrifuged at $4500 \mathrm{rpm}$ for $15 \mathrm{~min}$, and the supernatant was then used for electrophoresis.

Microwave treatment of bacterially degraded lignin was done to test removal of adsorbed protein by adding $2 \mathrm{~mL}$ of $P$ s. putida-treated lignin samples to a $10 \mathrm{~mL}$ pressure reaction vial using a lid to ensure the reaction was sealed and to prevent water evaporation. Microwaving was carried out with a CEM Discover SP automated microwave using a stir bar to ensure proper mixing. Microwaving was carried out at $95{ }^{\circ} \mathrm{C}$ for $30 \mathrm{~min}$ in order to denature any proteins present without boiling the sample.

Hydrogen Peroxide Breakdown of Lignin. In $250 \mathrm{~mL}$ conical flasks, control and test Kraft lignin KL1 samples $(5 \mathrm{~g} / \mathrm{L})$ were mixed in $75 \mathrm{mM}$ phosphate buffer with $2 \mathrm{~mL}$ of $30 \%(\mathrm{v} / \mathrm{v})(0.35 \mathrm{M})$ hydrogen peroxide at $37{ }^{\circ} \mathrm{C}$ in a shaker incubator mixing at $200 \mathrm{rpm}$. A $1 \mathrm{~mL}$ amount of sample was taken before and after $48 \mathrm{~h}$ incubation.

Hydrothermal Lignin Degradation. A $210 \mathrm{~mL}$ amount of 100 $\mathrm{g} / \mathrm{L}$ of alkali lignin in water was prepared before heating to $250{ }^{\circ} \mathrm{C}$ under self-generated pressure for $1 \mathrm{~h}$. A $10 \mathrm{~mL}$ sample was taken before heating, afterward the process water was filtered using paper to remove solids, and the solution produced was then used for gel electrophoresis.

Analysis of Low $M_{w}$ Species. The following samples were investigated for low molecular weight products: $100 \mathrm{~g} / \mathrm{L}$ Alkali lignin; $100 \mathrm{~g} / \mathrm{L}$ hydrothermally processed Alkali lignin; $100 \mathrm{~g} / \mathrm{L}$ KL1 Kraft lignin; $\mathrm{H}_{2} \mathrm{O}_{2}$ treated Alkali lignin; $10 \mathrm{~g} / \mathrm{L}$ vanillin and $10 \mathrm{~g} / \mathrm{L}$ guaiacol. The $\mathrm{H}_{2} \mathrm{O}_{2}$-treated Alkali lignin was produced by incubating at $37{ }^{\circ} \mathrm{C}$ in a $50 \mathrm{~mL}$ conical flask $10 \mathrm{~mL}$ of a solution containing $100 \mathrm{~g} / \mathrm{L}$ Alkali lignin, $70 \mathrm{mM}$ phosphate buffer, and $0.35 \mathrm{M}$ hydrogen peroxide, shaking at $180 \mathrm{rpm}$ for $48 \mathrm{~h}$. Electrophoresis was carried out in a minigel tank at $50 \mathrm{~V}$. A $50 \mu \mathrm{L}$ amount of each sample was mixed with $20 \mu \mathrm{L}$ of $50 \%(\mathrm{w} / \mathrm{v})$ glycerol and $20 \mu \mathrm{L}$ of $0.375 \mathrm{M} \mathrm{NaOH}$. A $20 \mu \mathrm{L}$ amount of this mixture was added to 8 of the gel wells (leaving the first and last wells empty).

Analysis of UV-absorbing species was carried out by taking $10 \mathrm{~mL}$ samples from the stirred anode end buffer before electrophoresis and every $15 \mathrm{~min}$ for $60 \mathrm{~min}$ (ensuring the current was switched off). The absorbance was measured at $280 \mathrm{~nm}$ using SB buffer as a blank. The mass of vanillin and guaiacol in the buffer was calculated using absorbance readings taken at $274 \mathrm{~nm}$. Extinction coefficients of $\varepsilon=$ $2739 / \mathrm{M} / \mathrm{cm}(274 \mathrm{~nm}, \mathrm{pH} 12)$ and $\varepsilon=3488 / \mathrm{M} / \mathrm{cm}(289 \mathrm{~nm}, \mathrm{pH} 12)$ were used to calculate the mass of vanillin and guaiacol present. ${ }^{42}$ As a control, a gel with only glycerol samples was run and the anode end buffer sampled in the same way with no UV-active species detected. 
NMR analysis of the low $M_{\mathrm{w}}$ species was carried out by removing all of the buffer from the gel tank $(450 \mathrm{~mL}$ total, ensuring the current was switched off). The solution was concentrated and extracted using ethyl acetate, and the solvent was evaporated in vacuo. The solids were then dissolved in $\mathrm{CDCl}_{3}$ and analyzed by ${ }^{1} \mathrm{HNMR}$ (ESI S5.1 and S5.2) with a Bruker Ascend $400 \mathrm{MHz}$ instrument.

Effects of Surfactants on Electrophoresis. The gels were made using either $\mathrm{pH} 8.3 \mathrm{TAE}$ buffer $(40 \mathrm{mM}$ tris base, $20 \mathrm{mM}$ acetic acid, and $1 \mathrm{mM}$ EDTA) or $\mathrm{pH} 8.75 \mathrm{SB}$ buffer $(36.4 \mathrm{mM}$ boric acid and 10 $\mathrm{mM}$ sodium hydroxide). Gels were made with $1 \%$ agarose and run at $100 \mathrm{~V}$ for $10 \mathrm{~min}$. A $5 \mu \mathrm{L}$ amount of of Kraft lignin KL2 or KL1 (1.5 $\mathrm{g} / \mathrm{L}$ ) was mixed with $2 \mu \mathrm{L}$ of $50 \%$ (w/v) glycerol and $2 \mu \mathrm{L}$ of either $10 \%(\mathrm{v} / \mathrm{v})$ SDS, $10 \%(\mathrm{v} / \mathrm{v})$ Triton X-100, 10\% (v/v/) DTAB, or water. Gels were imaged using UV trans excitation light and measuring emission at $602-650 \mathrm{~nm}$. A gel containing SDS running buffer and $1 \%$ agarose was mixed with $0.5 \mu \mathrm{g} / \mathrm{mL}$ ethidium bromide (after the gel was molten due to safety reasons). The gel was run at 50 $\mathrm{V}$, and images were taken after 15 and $30 \mathrm{~min}$ of electrophoresis. Control experiments were run without lignin using TAE buffer and $1 \%$ agarose. SDS was added to both the gel and the gel buffer to a final concentration of $0.1 \%$ (after microwaving, but before pouring to reduce foaming). No samples were loaded onto this gel. Gel electrophoresis was carried out at $100 \mathrm{~V}$ and stopped every $10 \mathrm{~min}$, and the gel was removed from the gel buffer in order to image.

\section{RESULTS AND DISCUSSION}

Electrophoresis Conditions. In developing a lignin electrophoresis method, the first task was to define a set of conditions that gave good separation and clearly visible bands. Table 1 shows the ranges of variables tested and the preferred migration conditions identified (see also ESI 1 ).

A stock solution of Kraft lignin $\mathrm{KL}^{43}$ was prepared by dissolving between 0.63 and $10 \mathrm{~g} \cdot \mathrm{L}^{-1}$ in water and adding $50 \%$ $(\mathrm{w} / \mathrm{v})$ glycerol to increase the density and viscosity to facilitate charging of samples to the gel, entry 1 . A lignin concentration of $5 \mathrm{~g} \cdot \mathrm{L}^{-1}$ was shown to give a clearly visible band, while that at $0.63 \mathrm{~g} \cdot \mathrm{L}^{-1}$ was faint and that at $10 \mathrm{~g} \cdot \mathrm{L}^{-1}$ was starting to smear, Figure 4 . While overloading with high lignin concentrations (up to $214 \mathrm{~g} \cdot \mathrm{L}^{-1}$ ) was possible, lateral diffusion occurred but makes possible preparative separation. It was later found that adding sodium hydroxide to the sample facilitated lignin dissolution and after charging to the gel and leaving $1 \mathrm{~h}$ to equilibrate in the pocket gave sharper more visible bands (ESI S1.3). Two different buffers were tested: Tris-acetate-EDTA (TAE), $\mathrm{pH} 8.3$ and sodium borate $\mathrm{SB}, \mathrm{pH}$ 8.8. TAE gave a diffuse smeared band with sample remaining in the pocket, while the borate buffer gave much sharper bands and better retention factor, entry 2 (ESI S1.8). Different $\mathrm{pH}$ adjustments to the buffer were made (ESI S1.9); however, the migration band was clearest at $\mathrm{pH} 8.8$, presumably as a result of ionization of the phenolic residues. The buffer strength selected was $36 \mathrm{mM}$, with one-half of this concentration giving less migration (ESI S1.6). Agarose concentrations of $0.5 \%, 1.0 \%$, and $2.0 \%(\mathrm{w} / \mathrm{v})$ were tested (ESI S1.4). The lowest concentration gave the highest $R_{f}$ but similar separation to the $1 \%$ gel (as measured by the length of the streaked band). Migration in the $2 \%$ gel was slow and the separation poor. Since the mechanical stability of $0.5 \%(\mathrm{w} / \mathrm{v})$ gels was poor, the $1 \%(\mathrm{w} / \mathrm{v})$ agarose gel was selected as the preferred concentration, entry 3. Voltages of $50-120 \mathrm{~V}$ were tested with the powerpack automatically adjusting the current for the system's resistance. Higher voltages resulted in overheating and distortion of the bands. A run time of $60 \mathrm{~min}$ at $50 \mathrm{~V}$ gave better resolution than $40 \mathrm{~min}$ at $120 \mathrm{~V}$ with a retention factor $\left(R_{f}\right)$ of around 0.3 and smearing between 0.125 and 0.45 (ESI
S1.4). To observe migrating species, gels are typically stained with dyes that interact to increase the UV fluorescence spectrum, enabling imaging equipment to scan and quantify the band intensity. Lignin fluoresces at $\sim 715 \mathrm{~nm}$ upon irradiation with light at $\sim 662 \mathrm{~nm}$, a convenient setting in the imaging system (Epi-far red), avoiding the need for stains, entries 7 and 8 (ESI 2). Further work to improve the lignin separation might explore more basic running buffers and hydrogels with different functionality and porosity.

Characterization of the Migration Band. A set of experiments was carried out to confirm the identity of the migrating band. A gel overloaded with lignin $(5 \mathrm{mg} / \mathrm{lane})$ was submitted to electrophoresis under the standard conditions (Figure 2; inset A). After running for $1 \mathrm{~h}$, a brown streak was

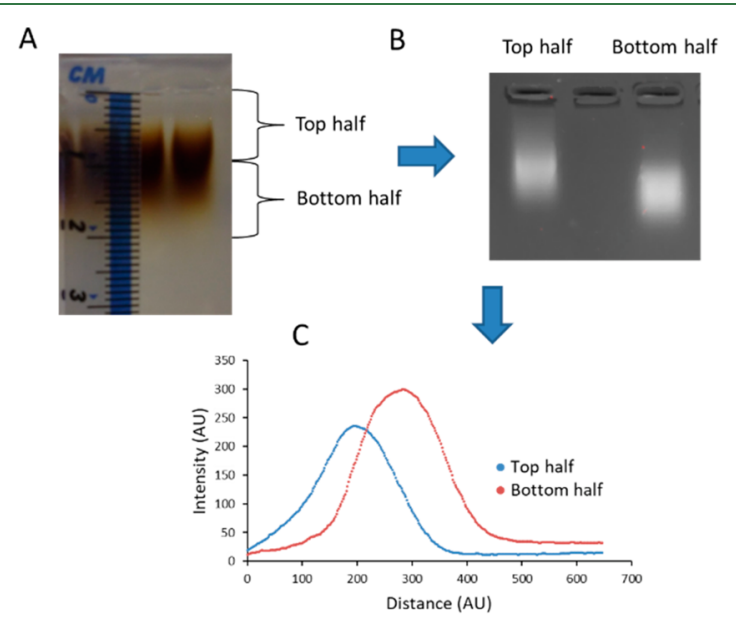

Figure 2. (A) Visible light image of minigel with Kraft KL1 lignin samples run under preferred conditions and ruler with millimeter graduations. (B) Second gel run with lignin extracted from the top half and bottom half of the band shown. (C) ImageJ trace of gel B showing fluorescence intensity vs migrating distance (arbitrary units) of lanes 1 (blue), 2 (empty), and 3 (red).

seen, and two sections (top half and bottom half) were cut from the gel and extracted by buffer overnight. The soluble extracts were then recharged to a second gel and submitted to electrophoresis for $1 \mathrm{~h}$ (Figure 2; inset B). The migration of the material in lanes 1 and 2 and their intensities were different and corresponded to the fractions cut from gel A. This was confirmed by the ImageJ trace showing different fluorescence intensity maxima and distances from the pocket, Figure 2, inset C. This confirmed that separation of the two lignin fractions could be achieved and that there was consistency in the migrating species. The cause of the bands overlapping is unclear but may be related to a change in lignin structure or associative complex due to the extraction procedure.

GPC was used to confirm the identity of the migrating band as lignin. Figure 3 shows lignin KL1 before and after electrophoresis with the entire band cut and extracted from the gel.

The profiles for both samples are similar; however the electrophoresed sample lacks the earlier eluting population (9-16 min retention time). This population, corresponding to a higher apparent $M_{w}$, might result either from lignin conformational changes or from aggregation due to 2-fold freeze drying. The apparent $M_{\mathrm{w}}$ and $M_{\mathrm{n}}$ of the standard were 12243 and $1076 \mathrm{~g} / \mathrm{mol}$, respectively; while they were 95929 and $1698 \mathrm{~g} / \mathrm{mol}$ for the extracted sample. The dispersities for 


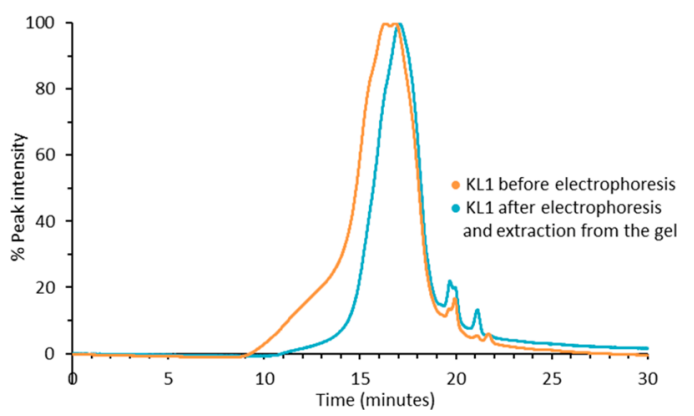

Figure 3. GPC plots of lignin KL1 before electrophoresis and after with extraction from the gel. Plots normalized with respect to the peak maximum.

KL1 before and after electrophoresis were 11.4 and 56.5, respectively. In addition to GPC, ${ }^{1} \mathrm{H}$ and $\mathrm{HMBC}$ NMR were carried out on the extracted lignin and showed the characteristic sets of peaks for $\mathrm{CHO}$ (9.5 ppm), aromatic $\mathrm{CH}(\sim 7$ $\mathrm{ppm}), \mathrm{CH} \gamma(\sim 5.5 \mathrm{ppm}), \mathrm{CH} \alpha(\sim 4.5 \mathrm{ppm})$, and $\mathrm{OMe}(3.75$ ppm) (ESI 3.2). ${ }^{31} \mathrm{P}$ NMR was attempted by derivatizing extracted and freeze-dried lignin with 2-chloro-4,4',5,5'tetramethyl-1,3,2-dioxaphospholane (TMDP). The spectrum showed an increase in side-reaction products (probably phosphite at around $15 \mathrm{ppm}$ and hydrolyzed TMDP at 132 ppm) probably due to remaining traces of $\mathrm{HCl}$ that hydrolyzed the reagent, making impossible the quantification of phenolic and aliphatic hydroxyl groups. MALDI-TOF MS was tried unsuccessfully; however, pyrolysis GC/MS of the extracted sample showed phenolic-related products guaiacol, 4-ethyland 4-propylguaiacol, and dimethoxy catechol and no agaroseor carbohydrate-related products such as furans (ESI 3.3). This combination of analytical results provided evidence that the migrating species was indeed lignin.

Quantification of Lignin Concentration. Figure 4 shows a concentration gradient of Kraft lignin KL1 prepared with a high $M_{\mathrm{w}}$ cutoff membrane on a $1 \%$ agarose minigel.

Conc. of lignin ( $g / L)$
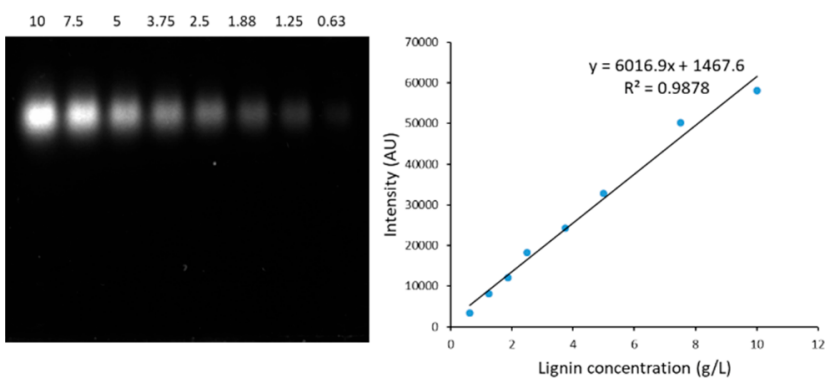

Figure 4. Serially diluted Kraft lignin KL1 run on a $1 \%$ agarose gel at $\mathrm{pH} 8.8,50 \mathrm{~V}$, for $60 \mathrm{~min}$, and calibration curve with points taken from ImageJ fluorescence maxima in each lane.

The serially diluted lignin produced a band which decreases in intensity with concentration. The gel was imaged, and fluorescence emission scans of each lane gave an intensity area that was plotted against concentration to obtain a calibration curve showing a best fit $R^{2}$ of 0.988 (ESI S1.11). It was found that more consistent bands and accurate traces could be obtained by casting onto a perfectly level gel bed avoiding dust, ignoring the outer lanes due to edge effects on the gel, and allowing samples $0.5-1 \mathrm{~h}$ to distribute into the full pocket volume rather than the bottom of the pocket (ESI S1.2). This result showed the electrophoresis and imaging techniques are reliable for generating a standard curve to quantify the concentration of lignin in an unknown sample, though they should be repeated for each type of lignin.

Electrophoresis of Different Lignins and Comparison with GPC. To assess the electrophoretic separation of different types and $M_{\mathrm{w}}$ fractions of lignin, the migration was compared to GPC elution. Figure 5, top row, shows a 38-lane gel comparing the migrations of three Organosolv (OS1-3), three Kraft (KL1, KL2, AL), and three Protobind (PB1-3) lignins with four repeats of each. Figure 5, middle row, shows GPC plots for each these lignins; the bottom row shows traces of the same lignins scanned from the electrophoresis gel. In the gel, differences in migration and fluorescence intensity were observed that presumably relate to differences in mass, charge, and shape.

The GPC and electrophoresis profiles showed high similarity. In Figure 5A, the overlaid GPC plots for the Protobind lignins $\mathrm{PB} 1-3$ show closely matched elution, which is mirrored in the electrophoresis in Figure 5D. A key difference, however, is the presence of additional peaks eluting after $19 \mathrm{~min}$ of the GPC profiles. These peaks correspond to low $M_{\mathrm{w}}$ compounds assigned to phenolic monomers and impurities arising from the derivatization procedure. In the electrophoresis traces, the closely matched overlay shows that the three lignin samples had a similar mass to charge and shape. Regarding Kraft lignins (Figure 5B and 5E), a similar difference between $\mathrm{KL} 2$ and $\mathrm{KL} 1$ profiles was observed by GPC and electrophoresis. Thus, results obtained by both methods were consistent, and because GPC is insensitive to charge, it can be deduced that the mass-to-charge ratio and shape of both KL2 and KL1 are similar. A distinct electrophoretic behavior was observed with the Alkali lignin. Indeed, it migrates significantly further than KL2 and KL1, which suggests a higher anionic charge or a smaller size than for KL2 and KL1. Unfortunately, GPC analysis of this lignin sample could not be performed as it was insoluble in THF and failed to derivatize. Finally, good agreement was obtained between the GPC and the electrophoresis profiles of the Organosolv lignins OS1, OS2, and OS3 in terms of peak shape and position (Figure $5 \mathrm{C}$ and $5 \mathrm{~F}$ ). The sample showing the highest $M_{\mathrm{w}}$, OS3, showed streaking from the pocket to the main band on electrophoresis. In contrast, the lowest $M_{\mathrm{w}}$ sample, OS1 (entry 7), showed a sharper, further migrating band that correlated with its lower $M_{w}$. In conclusion, these results indicate that electrophoresis could be used to segregate lignin samples according to their migration profile and in agreement with differences observed by GPC. Even slight differences between the samples could be detected by this method. The GPC-determined values of $M_{\mathrm{w}}, M_{\mathrm{n}}$ and polydispersities for each lignin calibrated against polystyrene standards are given in Table 2.

The set of data provides some degree of calibration for the electrophoresis gels and traces. Further work should develop a lignin $M_{\mathrm{w}}$ ladder, as used in polynucleotide electrophoresis.

Denaturing Gel Electrophoresis. Surfactants, such as sodium dodecyl sulfate (SDS), are used commonly to denature proteins and reduce shape and charge effects, though usually in polyacrylamide (SDS-PAGE) rather than agarose gels. To test the effect of surfactants on lignin migration in gels, SDS (anionic), Triton-X100 (neutral), or dodecyl trimethylammonium bromide (DTAB, cationic) was added to the samples and 


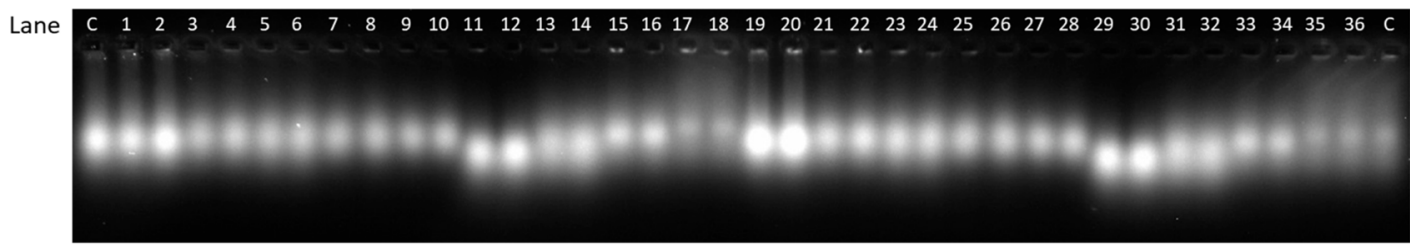

A

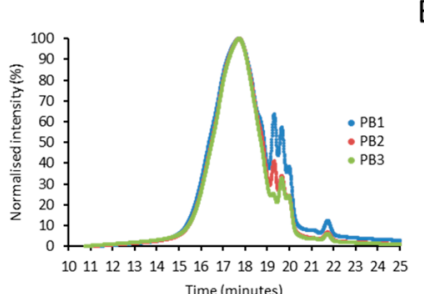

D

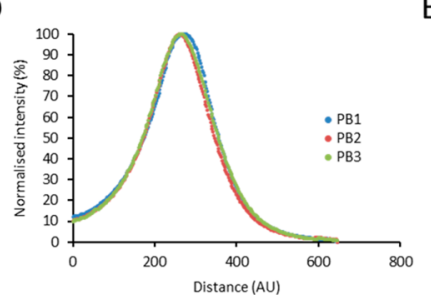

B
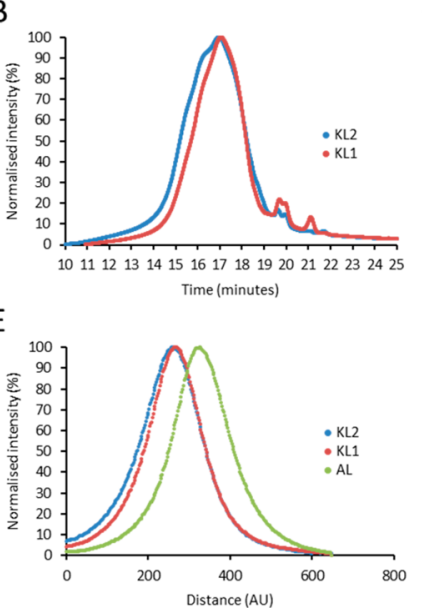

C

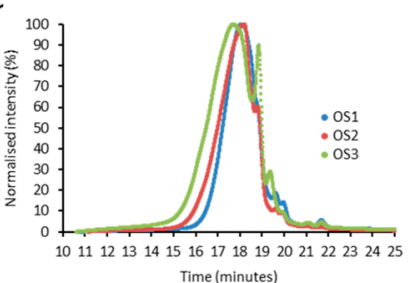

F

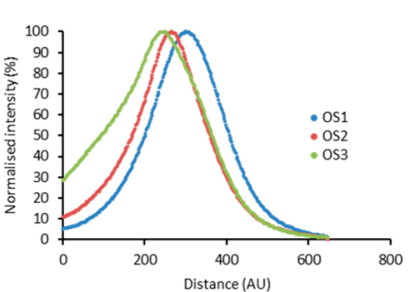

Figure 5. Comparison of different lignins by AGE and GPC. Top row: 38 lane lignin electrophoresis gel. Lanes: C = control; 1, 2, 19, 20 = PB1; 3 , 4, 21, 22 = PB2; 5, 6, 23, 24 = PB3; 7, 8, 25, 26 = KL2; 9, 10, 27, $28=\mathrm{KL} 1 ; 11,12,29,30=\mathrm{AL} ; 13,14,31,32=\mathrm{OS} 1 ; 15,16,33,34=\mathrm{OS} 2 ; 17,18$, 35, 36 = OS3. Middle row GPC plots: (A) Protobind lignins PB1, PB2 and PB3; (B) Kraft lignins KL2 and KL1; (C) Organosolv lignins OS1, OS2, and OS3. Bottom row gel electrophoresis traces taken from top row gel; duplicate lanes averaged and normalized to $100 \%$ intensity: (D) Protobind lignins PB1, PB2, and PB3; (E) Kraft lignins KL2, KL1, AL; (F) Organosolv lignins OS1, OS2, and OS3.

Table 2. $M_{\mathrm{n}}$ and $M_{\mathrm{w}}$ values $(\mathrm{g} / \mathrm{mol})$ for Kraft, Soda (Protobind), and Organosolv Samples Determined from GPC Chromatograms Using Polystyrene Standard Calibration

\begin{tabular}{cllll} 
entry & lignin sample & $M_{\mathrm{n}}$ & \multicolumn{1}{c}{$M_{\mathrm{w}}$} & dispersity \\
1 & Kraft KL2 & 1224 & 23042 & 18.8 \\
2 & Kraft KL1 & 1076 & 12243 & 11.4 \\
3 & Kraft AL & N/A & $\sim 10000^{a}$ & N/A \\
4 & Protobind PB1 & 560 & 5568 & 9.9 \\
5 & Protobind PB2 & 694 & 7657 & 11.0 \\
6 & Protobind PB3 & 720 & 9888 & 13.7 \\
7 & Organosolv OS1 & 634 & 3198 & 5.0 \\
8 & Organosolv OS2 & 787 & 5919 & 7.5 \\
9 & Organosolv OS3 & 862 & 8802 & 10.2
\end{tabular}

${ }^{a}$ Value provided by manufacturer.

run as previously on a $1 \%$ agarose gel. SDS gave a single sharp band with an increased fluorescence, Triton-X gave a smear centered around the pocket but extending to $R_{f} \approx 0.4$, and $\mathrm{DTAB}$ gave fluorescence around the pocket indicating a precipitate (ESI 6). SDS was evaluated further as neither the neutral nor the cationic surfactants improved separation. A problem encountered early on was that even small residual quantities of ethidium bromide (EtBr) left in the electrophoresis tanks complexed with the SDS to give fluorescent anionic bands that migrated down the gel, Figure 6 (left-hand gel). EtBr is a cationic dye used routinely in revealing DNA, though now superseded by SYBR safe. The SDS EtBr band is presumably SDS micelles ion paired with the EtBr.

Despite repeated washing of the tank, the only solution was to use a new one that had not been exposed to the dye. Now, when control samples were compared with SDS-treated

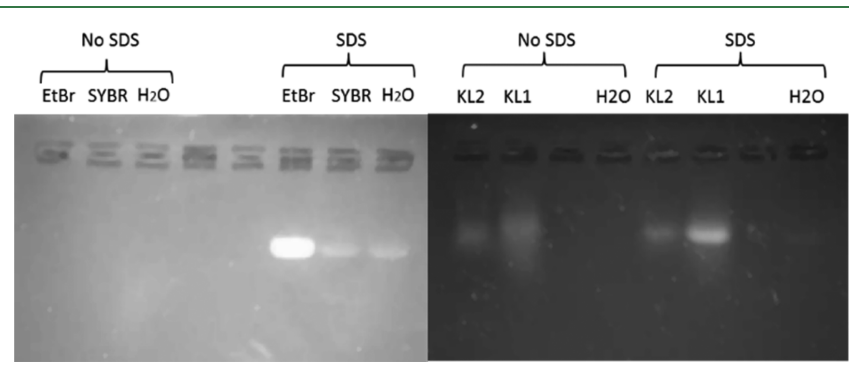

Figure 6. (Left) Minigel without lignin showing the interaction between SDS and EtBr. Visible bands with SYBR safe and water are due to residual $\mathrm{EtBr}$ in the tank interacting with the SDS. (Right) Minigel, free from EtBr, showing the difference in migration and fluorescence with SDS treatment of Kraft lignins KL2 and KL1.

samples, a sharper, more fluorescent band was observed (Figure 6, right-hand gel). The effect of the surfactant was to reduce the difference between $\mathrm{KL} 2$ and $\mathrm{KL} 1$ migration, indicating interaction with lignin to reduce the mass to charge and shape effects, but also separation of species. The nature of the SDS-lignin complex is unclear, but it seems that hydrophobic interactions are involved. More work is required to determine potential benefits of using surfactants in lignin electrophoresis.

Investigation of Lignin Depolymerization. A series of experiments was carried out on the Kraft KL1 lignin to compare the effects of different lignin deconstruction methods through electrophoretic differences, Table 3. These methods were oxidation by a laccase enzyme preparation made specifically for this purpose, ${ }^{36,44}$ conversion by two bacteria, one of which was engineered to accumulate small molecule intermediates, ${ }^{41,45}$ oxidation by hydrogen peroxide, ${ }^{46}$ and hydrothermal treatment involving superheated water. 
Table 3. Comparison of Different Methods for Kraft KL1 Deconstruction $^{a}$

\begin{tabular}{clccc} 
entry & \multicolumn{1}{c}{ method } & $\begin{array}{c}\text { treatment } \\
\text { time }(\mathrm{h})\end{array}$ & $\begin{array}{c}\text { starting } \\
\text { concentration } \\
(\mathrm{g} / \mathrm{L})\end{array}$ & $\begin{array}{c}\text { fluorescence } \\
\text { change }(\%)\end{array}$ \\
1 & laccase & 72 & 5.0 & -15 \\
2 & $\begin{array}{c}\text { Ps.putida } \\
\text { KT2440 }\end{array}$ & $264^{a}$ & 1.5 & $-6^{b, d}$ \\
3 & Rh.jostii RHA1 & $240^{e}$ & 1.5 & $-26^{c_{f} f}$ \\
4 & $\mathrm{H}_{2} \mathrm{O}_{2}$ & 48 & 5.0 & -20 \\
$5^{g}$ & $\mathrm{H}_{2} \mathrm{O}_{2}$ & 48 & 5.0 & -38 \\
$6^{g}$ & hydrothermal & 1 & 95 & $-30^{h}$
\end{tabular}

${ }^{a}$ For more details, see ESI 4.2. ${ }^{b}$ As determined from calibrated curve areas from electrophoresis traces. ${ }^{c}$ Worked up by microwave treatment before electrophoresis. ${ }^{d}$ Increase in high $M_{\mathrm{w}}$ species. ${ }^{e}$ With $0.1 \mathrm{~g} \cdot \mathrm{L}^{-1}$ vanillic acid. ${ }^{f}$ Increase in low $M_{\mathrm{w}}$ species. ${ }^{g}$ Alkali lignin. ${ }^{h}$ Twenty-two percent of mass changed from soluble to nonmigrating solid.

From these experiments, lignin depolymerization was assessed by measuring the reduction in fluorescence area under the curves generated by scanning each lane in the gel, Figure 7.

Incubation of Kraft $\mathrm{KL} 1$ lignin with the laccase at $37{ }^{\circ} \mathrm{C}$ for $72 \mathrm{~h}$ (ESI S4.1) induced a reduction in the lignin band fluorescence of $15 \%$ with respect to the controls, Table 3 , entry 1. Interestingly, the trace showed a lower proportion of high $M_{\mathrm{w}}$ species, a reduction in the main band intensity, but no change in the further migrating, low $M_{\mathrm{w}} /$ charge, species. This suggested that the enzyme might cleave interunit bonds but that the released lower $M_{\mathrm{w}}$ compounds underwent recondensation which is in agreement with laccase-related literature. ${ }^{47,48}$ The changes in electrophoretic profile matched those obtained by GPC.

For the bacterial lignin digestion, the wild-type strain Ps. putida KT2440 and blocked mutant Rh. jostii RHA1 were both grown on lignin KL1 for 10 days; the former strain was supplemented with glucose to initiate growth, while the latter strain was supplemented with vanillic acid to induce enzymes in the aromatic degradation pathways. ${ }^{45}$ Initial and final samples were centrifuged to separate the bacteria, and supernatants were analyzed by electrophoresis. In contrast to laccase, the bacterial treatments led to an increase in the fluorescence intensity of the lignin band, ESI 4.2. This result was unexpected but might be structural changes due to adsorption of extracellular enzymes. To test this, samples were treated with proteinase $\mathrm{K}$; however, no change in the lignin fluorescence was seen. It was found that a $30 \mathrm{~min}$ microwave heat treatment was able to denature or desorb the attached species, allowing the effect of lignin digestion alone to be seen. Comparison with the controls indicated that Ps. putida had depolymerized $6 \%$ of the KL1 lignin and Rh. jostii $26 \%$ (Table 3 , entries 2 and 3). The shape of the 10-day electrophoresis trace for $R h$. jostii showed a slight increase in the proportion of low $M_{\mathrm{w}}$ species with a slightly shifted maximum and less fluorescence than the control.

Treatment of Kraft KL1 with $\mathrm{H}_{2} \mathrm{O}_{2}\left(0.35 \mathrm{M}, 37{ }^{\circ} \mathrm{C}, 48 \mathrm{~h}\right)$ led to a $20 \%$ decrease in the fluorescence intensity of the lignin band (Table 3 (entry 4); ESI 4.3). This decrease was even more pronounced (38\%) by treatment of the Alkali lignin (entry 5) tested for comparison, showing it was more susceptible to breakdown than Kraft lignin. In both cases, the band profiles showed a lower proportion of higher $M_{\mathrm{w}}$
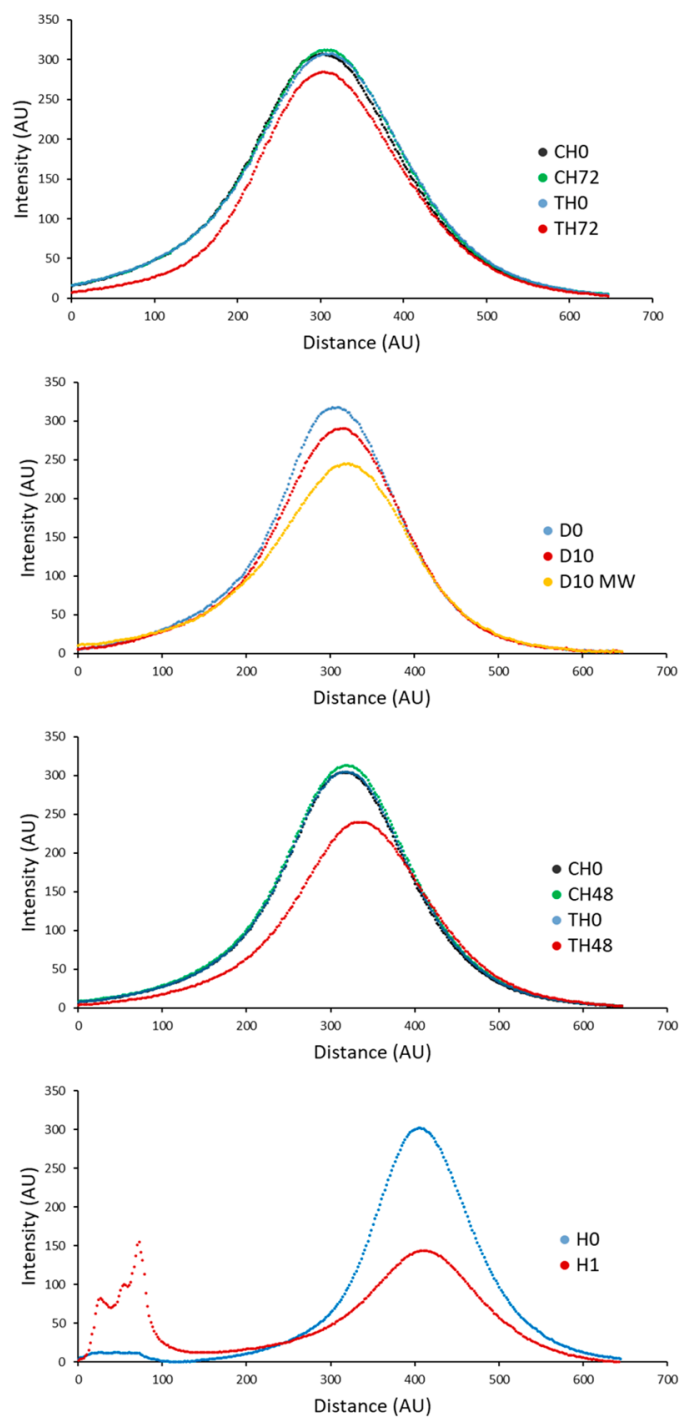

Figure 7. Electrophoretic migration fluorescence traces of Kraft KL1 after depolymerization treatment: $\mathrm{C}=$ control, $\mathrm{T}=$ treated, $\mathrm{H}=$ hour, $\mathrm{D}=$ Day. Top to bottom: laccase enzyme; Rh. jostii bacteria; $\mathrm{H}_{2} \mathrm{O}_{2}$; hydrothermal. See ESI 4 for gels. MW = microwaved.

species along with a general decrease in intensity across the whole lane. This indicates nonspecific structural modification that affects the lignin fluorescence, a bleaching effect.

Hydrothermal treatment of soluble Kraft AL lignin (95 g/L) led to formation of a solid, $22 \%(\mathrm{w} / \mathrm{w})$. Some carbonization was expected for the conditions used, $1 \mathrm{~h}$ at $250{ }^{\circ} \mathrm{C}$. The solid was removed by filtration, and electrophoresis of the soluble material revealed a decrease in the overall fluorescence intensity of $30 \%$ compared to the control (ESI 4.4). The trace showed two distinct bands: one of nonmigrating material retained around the pocket ( $22 \%$ of the fluorescence) and a band less intense but migrating the same distance as the untreated control (78\% of the fluorescence), Table 3 (entry 6) and Figure 7 . This implies that the mechanism of hydrothermal carbonization is through loss of aromaticity and deoxygenation. ${ }^{49}$ Carbonization of lignin is well known, ${ }^{50}$ but it is novel to observe changes this way and may help in the development of more selective methods.

Analysis of low $M_{w}$ Species. Having observed changes in the main lignin band in each of the degradation methods, experiments were carried out to understand the mass balance 


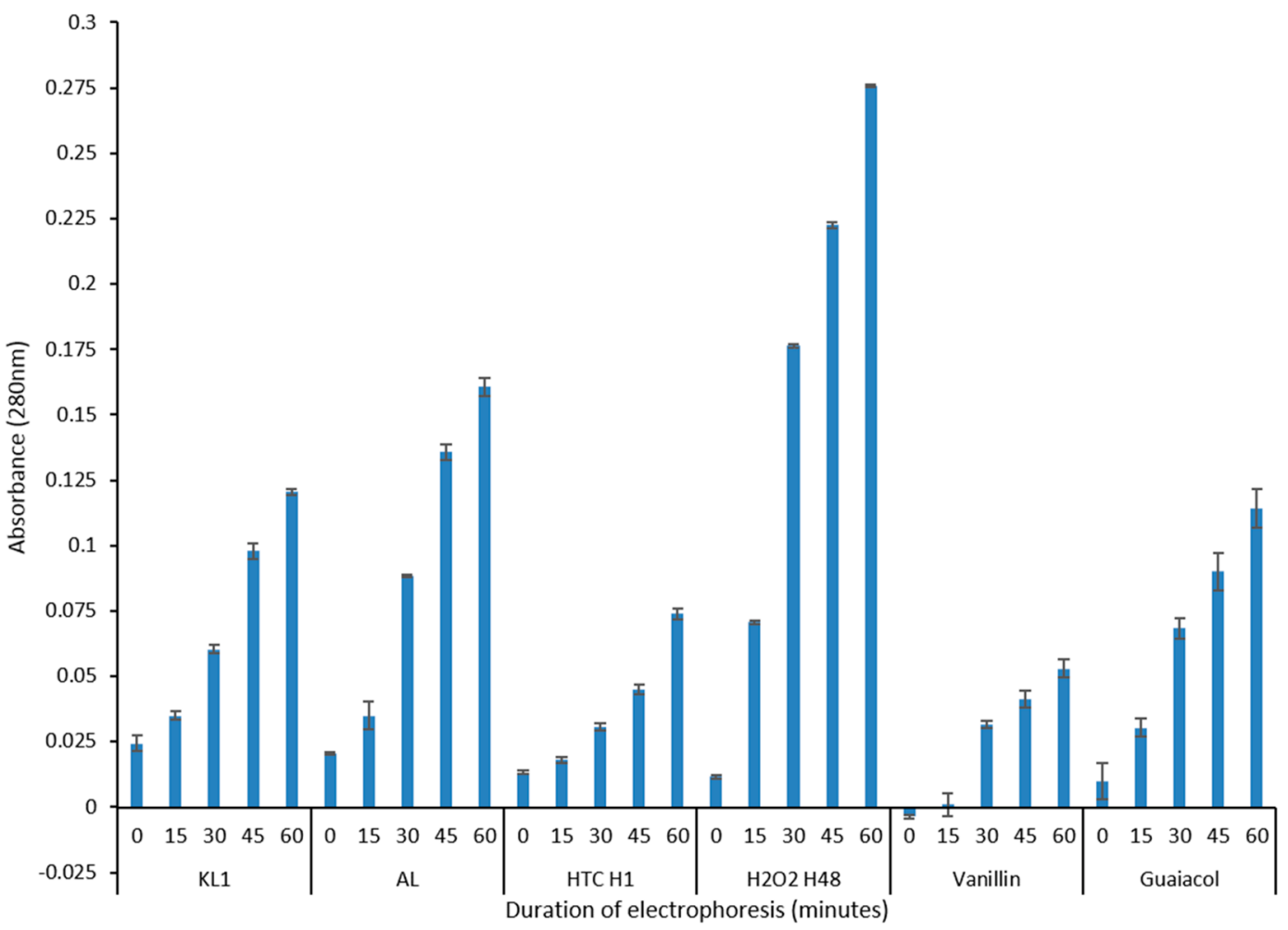

Figure 8. UV absorptions of species eluting from electrophoresis gels with samples taken from the anode buffer tank at $0,15,30,45$, and 60 min time intervals. Each sample loaded onto the gel contained $16.7 \mu \mathrm{L}$ of $100 \mathrm{~g} / \mathrm{L}$ lignin: KL1 untreated Kraft lignin KL1; AL alkali lignin; HTC H1 hydrothermally treated $\mathrm{AL}, 1 \mathrm{~h} ; 0.35 \mathrm{M} \mathrm{H}_{2} \mathrm{O}_{2}$ treated $\mathrm{KL} 1$ after $48 \mathrm{~h} ; 1 \%$ (w/v) vanillin; $1 \%(\mathrm{w} / \mathrm{v}$ ) guaiacol. Error bars generated from four repeats (ESI 5).

by seeing whether far-migrating species were formed that accumulate in the anode end buffer. Electrophoresis was carried out with Kraft KL1, Alkali lignin, hydrothermal, and $\mathrm{H}_{2} \mathrm{O}_{2}$-treated samples along with controls of vanillin, guaiacol, and empty gel (ESI5.1). The current was switched off at 15 min intervals to sample the buffer tank and measure the UV absorbance. After $60 \mathrm{~min}$ the main lignin band remained in the gel, so only low $M_{\mathrm{w}}$ molecules were detected, Figure 8 .

In each experiment, the UV absorption increased with time, indicating an accumulation of low $M_{\mathrm{w}}$ anionic species. Both untreated lignins appeared to contain rapidly migrating species that absorb at $280 \mathrm{~nm}$. Interestingly, KL1 hydrothermally treated for $1 \mathrm{~h}$ had a lower concentration, or UV inactive, fast migrating species which correlates with the observations in Figure $7 . \mathrm{H}_{2} \mathrm{O}_{2}$-treated $\mathrm{KL} 1$ gave an absorption that increased over the hour to almost twice that of the KL1 control and is commensurate with the decrease in fluorescence seen for the main lignin band. It is useful to confirm that vanillin and guaiacol anions migrate rapidly through the gel but take $>10$ min to emerge. On the basis of their reported extinction coefficients, ${ }^{42}$ the concentrations in the tank are 19 and $24 \mu \mathrm{M}$ respectively, which provides an estimate of the concentration of the species in the other samples.

One experiment was done in which the buffer solution from the anode end of the $\mathrm{KL} 1, \mathrm{H}_{2} \mathrm{O}_{2}$ experiment was concentrated and solvent extracted. ${ }^{1} \mathrm{H}$ NMR of the sample showed unassigned signals at $1,3.5,4$, and $7 \mathrm{ppm}$ (ESI 5). Interestingly, the aromatic coupling patterns indicated a 3,4disubstituted aromatic. Further work is ongoing to characterize the breakdown products. This study shows promise in separating small molecules from lignin digestates.
In summary, a useful AGE method has been developed to help characterize different lignins based on mass, charge, and shape. As little as $10 \mu \mathrm{g}$ of lignin is required in the sample, and this compares to $10 \mathrm{mg}$ for GPC analysis Electrophoretic conditions have been identified to separate species according to their apparent $M_{\mathrm{w}}$. These include gel density, buffer, $\mathrm{pH}$, sample loading, applied voltage, and migration time and for gel imaging, excitation and fluorescence emission wavelengths and quantification of retention factors and band intensities. Once edge effects, level gel casting, and equilibration of samples in pockets were understood, both mini 8-lane, and maxi 40-lane gels were used with excellent reproducibility, as seen in the small variations in repeat experiments. Overlaid curves were referenced to migration from the leading edge of the pocket. In some cases, it was useful to normalize fluorescence values to $100 \%$ so that small structural differences in lignin migration could be observed. Fluorescence intensities were measured from traces for serially diluted lignins, enabling calibration curves with high linear correlation and subsequent determination of unknown sample concentrations, proving that structural variations do not affect fluorescence. Use of SDS surfactant identified a problem with the electrophoresis of micelles and interaction with cationic dyes. Once these effects were eliminated, SDS was shown to complex with lignin by reducing mass-charge and shape effects. This was exemplified using Kraft lignins $\mathrm{KL} 2$ and $\mathrm{KL} 1$, whose structure was modified to give the same migration velocities and less smearing. The benefits of using SDS with lignin are not yet clear, and more work is required to define these. Larger quantities of purified lignin were prepared by overloading large gels, cutting, and extracting the lignin band, and these were used in GPC experiments to determine their mass and 
polydispersity. Further work will look at analyzing the extracted lignin by NMR, which has so far been unsuccessful due to the size of sample required and residual acidity. Electrophoresis of different types of Kraft, Alkali, Organosolv, and soda (Protobind) lignins has shown differences in migration behaviors that correlate with GPC elution profiles and can be used to assess differences in $M_{\mathrm{w}}$ and charge. For example, Alkali lignin migrates more quickly than Kraft lignin KL1 despite being similar in $M_{w}$, indicating a higher charge to mass or different shape. It has not yet been possible to generate a $M_{\mathrm{w}}$ ladder to correlate with migrating bands, as used commonly in DNA and protein analysis. AGE was used to compare different methods of lignin breakdown. A 6-38\% decrease in mass/charge was seen in enzymatic, bacterial, hydrothermal, and hydrogen peroxide treatments over different treatment times. Concurrent with this, low $M_{\mathrm{w}}$ species were observed to migrate more rapidly through the gel. Further work is aiming to characterize these and to see whether a preparative method can be devised that might provide a simple separation of lignin polymer from monomers. We think researchers will find the AGE method useful in progressing their research into lignin to help exploit this biorenewable resource.

\section{ASSOCIATED CONTENT}

\section{SI Supporting Information}

The Supporting Information is available free of charge at https://pubs.acs.org/doi/10.1021/acs.jafc.0c06308.

Electrophoresis materials and methods; evidence that migrating bands are lignin; optimization of agarose electrophoresis conditions; lignin degradation studies; analysis of low $M_{\mathrm{w}}$ species; effects of surfactants on electrophoresis (PDF)

\section{AUTHOR INFORMATION}

\section{Corresponding Author}

A. John Blacker - Institute of Process Research and Development, School of Chemistry and School of Chemical and Process Engineering, University of Leeds, Leeds LS2 9JT, United Kingdom; 이이.org/0000-0003-4898-2712; Phone: +44 113 3438239; Email: j.blacker@leeds.ac.uk

\section{Authors}

Christopher A. Holt - Institute of Process Research and Development, School of Chemistry and School of Chemical and Process Engineering, University of Leeds, Leeds LS2 9JT, United Kingdom

Betty Cottyn - Institut Jean-Pierre Bourgin, INRAE, AgroParisTech, Université Paris-Saclay, Versailles 78000, France

Stephanie Baumberger - Institut Jean-Pierre Bourgin, INRAE, AgroParisTech, Université Paris-Saclay, Versailles 78000, France

Krisztina Kovacs-Schreiner - Biome Bioplastics Limited, Southampton SO40 4BL, United Kingdom

Complete contact information is available at:

https://pubs.acs.org/10.1021/acs.jafc.0c06308

\section{Funding}

We thank the EPSRC CDT in Bioenergy at the University of Leeds (EP/L014912/1] and Biome Bioplastics Ltd. for support of C.H. This work was supported by ADEME [No.
1401C0066] and by the European Commission [ERA-IB-14055] in the framework of the LIGBIO project. The IJPB research unit benefits from the support of the LabEx Saclay Plant Sciences-SPS (ANR-10-LABX-552 0040-SPS).

\section{Notes}

The authors declare no competing financial interest.

\section{ACKNOWLEDGMENTS}

Wouter J. J. Huijgen (Energy Center of The Netherlands) is acknowledged for providing the Organosolv lignin samples. Amel Majira is sincerely acknowledged for technical support at IJPB. This paper is dedicated with much gratitude to Professors Jean-Marie Lehn and Jean-Paul Behr.

\section{REFERENCES}

(1) Zhong, R.; Ye, Z.-H. Transcriptional regulation of lignin biosynthesis. Plant Signaling Behav. 2009, 4 (11), 1028-1034.

(2) Gillet, S.; Aguedo, M.; Petitjean, L.; Morais, A. R. C.; da Costa Lopes, A. M.; Łukasik, R. M.; Anastas, P. T. Lignin transformations for high value applications: towards targeted modifications using green chemistry. Green Chem. 2017, 19 (18), 4200-4233.

(3) Schutyser, W.; Renders, T.; Van den Bosch, S.; Koelewijn, S. F.; Beckham, G. T.; Sels, B. F. Chemicals from lignin: an interplay of lignocellulose fractionation, depolymerisation, and upgrading. Chem. Soc. Rev. 2018, 47 (3), 852-908.

(4) Ragauskas, A. J.; Beckham, G. T.; Biddy, M. J.; Chandra, R.; Chen, F.; Davis, M. F.; Davison, B. H.; Dixon, R. A.; Gilna, P.; Keller, M.; Langan, P.; Naskar, A. K.; Saddler, J. N.; Tschaplinski, T. J.; Tuskan, G. A.; Wyman, C. E. Lignin Valorization: Improving Lignin Processing in the Biorefinery. Science 2014, 344 (6185), 1246843.

(5) Zhao, Y.; King, G.; Kwan, M. H. T.; Blacker, A. J. A Mild and Selective Method for the Catalytic Hydrodeoxygenation of Cyanurate Activated Phenols in Multiphasic Continuous Flow. Org. Process Res. Dev. 2016, 20 (11), 2012-2018.

(6) Lange, H.; Decina, S.; Crestini, C. Oxidative upgrade of lignin Recent routes reviewed. Eur. Polym. J. 2013, 49 (6), 1151-1173.

(7) Beckham, G. T.; Johnson, C. W.; Karp, E. M.; Salvachúa, D.; Vardon, D. R. Opportunities and challenges in biological lignin valorization. Curr. Opin. Biotechnol. 2016, 42, 40-53.

(8) Andrianova, A. A.; Yeudakimenka, N. A.; Lilak, S. L.; Kozliak, E. I.; Ugrinov, A.; Sibi, M. P.; Kubátová, A. Size exclusion chromatography of lignin: The mechanistic aspects and elimination of undesired secondary interactions. Journal of Chromatography A 2018, 1534, 101-110.

(9) Giummarella, N.; Pu, Y.; Ragauskas, A. J.; Lawoko, M. A critical review on the analysis of lignin carbohydrate bonds. Green Chem. 2019, 21 (7), 1573-1595.

(10) Chen, H. Lignocellulose biorefinery feedstock engineering. In Lignocellulose Biorefinery Engineering, Chen, H., Ed.; Woodhead Publishing, 2015; Chapter 3, pp 37-86.

(11) Hatfield, R.; Fukushima, R. S. Can Lignin Be Accurately Measured? Crop Sci. 2005, 45 (3), 832-839.

(12) Singleton, V. L.; Orthofer, R.; Lamuela-Raventós, R. M. Analysis of total phenols and other oxidation substrates and antioxidants by means of folin-ciocalteu reagent. Methods in Enzymology; Academic Press: 1999; Vol. 299, pp 152-178.

(13) Gramss, G. Reappraising a Controversy: Formation and Role of the Azodication (ABTS2+) in the Laccase-ABTS Catalyzed Breakdown of Lignin. Fermentation 2017, 3 (2), 27.

(14) Liu, D.; Li, Y.; Qian, Y.; Xiao, Y.; Du, S.; Qiu, X. Synergistic Antioxidant Performance of Lignin and Quercetin Mixtures. ACS Sustainable Chem. Eng. 2017, 5 (9), 8424-8428.

(15) Baumberger, S.; Abaecherli, A.; Fasching, M.; Gellerstedt, G.; Gosselink, R.; Hortling, B.; Li, J.; Saake, B.; de Jong, E. Molar mass determination of lignins by size-exclusion chromatography: towards standardisation of the method. Holzforschung 2007, 61 (4), 459-468. 
(16) Zhang, L.; Gellerstedt, G. Quantitative 2D HSQC NMR determination of polymer structures by selecting suitable internal standard references. Magn. Reson. Chem. 2007, 45 (1), 37-45.

(17) Du, X.; Gellerstedt, G.; Li, J. Universal fractionation of lignincarbohydrate complexes (LCCs) from lignocellulosic biomass: an example using spruce wood. Plant J. 2013, 74 (2), 328-338.

(18) Asikkala, J.; Tamminen, T.; Argyropoulos, D. S. Accurate and Reproducible Determination of Lignin Molar Mass by Acetobromination. J. Agric. Food Chem. 2012, 60 (36), 8968-8973.

(19) Chen, F.; Li, J. Aqueous Gel Permeation Chromatographic Methods for Technical Lignins. J. Wood Chem. Technol. 2000, 20 (3), 265-276.

(20) Chum, H. L.; Johnson, D. K.; Tucker, M. P.; Himmel, M. E. Some Aspects of Lignin Characterization by High Performance Size Exclusion Chromatography Using Styrene Divinylbenzene Copolymer Gels. Holzforschung 1987, 41 (2), 97.

(21) Cathala, B.; Saake, B.; Faix, O.; Monties, B. Association behaviour of lignins and lignin model compounds studied by multidetector size-exclusion chromatography. Journal of Chromatography A 2003, 1020 (2), 229-239.

(22) Gidh, A. V.; Decker, S. R.; Vinzant, T. B.; Himmel, M. E.; Williford, C. Determination of lignin by size exclusion chromatography using multi angle laser light scattering. Journal of Chromatography $A$ 2006, 1114 (1), 102-110.

(23) Tolbert, A.; Akinosho, H.; Khunsupat, R.; Naskar, A. K.; Ragauskas, A. J. Characterization and analysis of the molecular weight of lignin for biorefining studies. Biofuels, Bioprod. Biorefin. 2014, 8 (6), 836-856.

(24) Braaten, S. M.; Christensen, B. E.; Fredheim, G. E. Comparison of Molecular Weight and Molecular Weight Distributions of Softwood and Hardwood Lignosulfonates. J. Wood Chem. Technol. 2003, 23 (2), 197-215.

(25) Ludwig, C. H.; Nist, B. J.; McCarthy, J. L. Lignin. XII.1 The High Resolution Nuclear Magnetic Resonance Spectroscopy of Protons in Compounds Related to Lignin. J. Am. Chem. Soc. 1964, 86 (6), 1186-1196.

(26) Balakshin, M.; et al. Quantification of lignin-carbohydrate linkages with high-resolution NMR spectroscopy. Planta 2011, 233 (6), 1097-1110.

(27) Capanema, E. A.; Balakshin, M. Y.; Kadla, J. F. A Comprehensive Approach for Quantitative Lignin Characterization by NMR Spectroscopy. J. Agric. Food Chem. 2004, 52 (7), 18501860.

(28) Hjertén, S. Zone electrophoresis in columns of agarose suspensions. Journal of Chromatography A 1963, 12, 510-526.

(29) Lee, P. Y.; Costumbrado, J.; Hsu, C.-Y.; Kim, Y. H. Agarose Gel Electrophoresis for the Separation of DNA Fragments. J. Visualized Exp. 2012, No. 62, No. e3923.

(30) Greaser, M. L.; Warren, C. M. Protein Electrophoresis in Agarose Gels for Separating High Molecular Weight Proteins. In Protein Electrophoresis: Methods and Protocols, Kurien, B. T., Scofield, R. H., Eds.; Humana Press: Totowa, NJ, 2012; pp 111-118.

(31) Clar, J. G.; Silvera Batista, C. A.; Youn, S.; Bonzongo, J.-C. J.; Ziegler, K. J. Interactive Forces between Sodium Dodecyl SulfateSuspended Single-Walled Carbon Nanotubes and Agarose Gels. J. Am. Chem. Soc. 2013, 135 (47), 17758-17767.

(32) Schubert, W. J.; Passannante, A.; Stevens, G. d.; Bier, M.; Nord, F. F. Investigations on Lignin and Lignification. XIII. Electrophoresis of Native and Enzymatically Liberated Lignins1. J. Am. Chem. Soc. 1953, 75 (8), 1869-1873.

(33) Da Re, V.; Papinutti, L. Black Liquor Decolorization by Selected White-Rot Fungi. Appl. Biochem. Biotechnol. 2011, 165 (2), 406-415.

(34) Niku-Paavola, M.-L. Isoelectric focusing electrophoresis of lignin. Anal. Biochem. 1991, 197 (1), 101-103.

(35) Gebremeskel, G. G.; Aldaeus, F. Determination of lignin content in kraft black liquors by capillary zone electrophoresis (CZE). Holzforschung 2013, 67 (8), 887.
(36) https://en.wikipedia.org/wiki/Agarose gel electrophoresis (accessed 25/03/2020

(37) Barton, J. K.; Raphael, A. L. Photoactivated stereospecific cleavage of double-helical DNA by cobalt(III) complexes. J. Am. Chem. Soc. 1984, 106 (8), 2466-2468.

(38) Blacker, A. J.; Jazwinski, J.; Lehn, J. M.; Wilhelm, F. X. Photochemical cleavage of DNA by 2,7-diazapyrenium cations. J. Chem. Soc., Chem. Commun. 1986, No. 13, 1035-1037.

(39) Aguié-Béghin, V.; Foulon, L.; Soto, P.; Crônier, D.; Corti, E.; Legée, F.; Cézard, L.; Chabbert, B.; Maillard, M.-N.; Huijgen, W. J. J.; Baumberger, S. Use of Food and Packaging Model Matrices to Investigate the Antioxidant Properties of Biorefinery Grass Lignins. J. Agric. Food Chem. 2015, 63 (45), 10022-10031.

(40) MetGen, MetZyme®LIGNO, http://www.metgen.com/ products/metzyme-ligno/metzyme-ligno-v1/ (accessed 25/03/2020).

(41) Salvachúa, D.; Karp, E. M.; Nimlos, C. T.; Vardon, D. R.; Beckham, G. T. Towards lignin consolidated bioprocessing: simultaneous lignin depolymerization and product generation by bacteria. Green Chem. 2015, 17 (11), 4951-4967.

(42) Lemon, H. W. The Effect of Alkali on the Ultraviolet Absorption Spectra of Hydroxyaldehydes, Hydroxyketones and other Phenolic Compounds. J. Am. Chem. Soc. 1947, 69 (12), 2998-3000.

(43) Lignin procured from 8317267 Canada Inc.

(44) Hämäläinen, V.; Grönroos, T.; Suonpää, A.; Heikkilä, M. W.; Romein, B.; Ihalainen, P.; Malandra, S.; Birikh, K. R. Enzymatic Processes to Unlock the Lignin Value. Front. Bioeng. Biotechnol. 2018, 6, 20-20.

(45) Mycroft, Z.; Gomis, M.; Mines, P.; Law, P.; Bugg, T. D. H. Biocatalytic conversion of lignin to aromatic dicarboxylic acids in Rhodococcus jostii RHAl by re-routing aromatic degradation pathways. Green Chem. 2015, 17 (11), 4974-4979.

(46) Gierer, J.; Jansbo, K. Formation of Hydroxyl Radicals from Hydrogen Peroxide and their Effect on Bleaching of Mechanical Pulps. J. Wood Chem. Technol. 1993, 13 (4), 561-581.

(47) Asina, F. N. U.; Brzonova, I.; Kozliak, E.; Kubátová, A.; Ji, Y. Microbial treatment of industrial lignin: Successes, problems and challenges. Renewable Sustainable Energy Rev. 2017, 77, 1179-1205.

(48) Areskogh, D.; Nousiainen, P.; Li, J.; Gellerstedt, G.; Sipilä, J.; Henriksson, G. ORIGINAL RESEARCH: Sulfonation of phenolic end groups in lignin directs laccase-initiated reactions towards crosslinking. Ind. Biotechnol. 2010, 6 (1), 50-59.

(49) Curtze, J. H.; Bär, F.; Steffan, J.; Dörr, T.; Vogel, H. Hydrothermal Carbonization of Lignin with Vanillin as a Model Component. Chem. Eng. Technol. 2017, 40 (6), 1190-1195.

(50) Kang, S.; Li, X.; Fan, J.; Chang, J. Characterization of Hydrochars Produced by Hydrothermal Carbonization of Lignin, Cellulose, d-Xylose, and Wood Meal. Ind. Eng. Chem. Res. 2012, 51 (26), 9023-9031. 